\title{
Treatment of type 2 diabetes in chronic kidney disease: a case for linagliptin in the treatment of diabetes in severe renal impairment
}

This article was published in the following Dove Press journal:

Diabetes, Metabolic Syndrome and Obesity:Targets and Therapy

I October 2013

Number of times this article has been viewed

\section{David Scott}

Clinical Research Development Associates, Rosedale, NY, USA
Correspondence: David Scott Clinical Research Development Associates, I Cross Island Plaza, LL4, Rosedale, NY I |413, USA

Tel +I 7182764750

Fax + I 718276 457|

Email dscott@clinicalresearchdevelopment. org

\begin{abstract}
Diabetes is the leading cause of chronic kidney disease, and the prevalence of both diseases is rising worldwide. Treatment of type 2 diabetes is difficult in patients with chronic kidney disease because most oral antidiabetic agents are affected by renal function and their use may be contraindicated in this patient population. Antidiabetic agents that can be used in patients with type 2 diabetes and declining renal function are needed. Incretin-based therapies, such as dipeptidyl peptidase-4 inhibitors, are a recent therapeutic class of glucose-lowering agents that may offer an effective treatment option in patients with chronic kidney disease. Within the dipeptidyl peptidase- 4 class, linagliptin has a unique profile with a primarily nonrenal route of elimination, requiring no dose adjustment in patients with chronic kidney disease. This communication summarizes the findings of a 1-year, randomized, double-blind, placebo-controlled study demonstrating the favorable safety and efficacy profile of linagliptin in patients with type 2 diabetes and severe renal impairment.
\end{abstract}

Keywords: renal impairment, incretin, DPP-4 inhibitor, type 2 diabetes

\section{Commentary}

The treatment of type 2 diabetes in advanced chronic kidney disease poses a tremendous challenge in our clinical practices. One of the most difficult issues in this patient population is that loss of renal function results in marked metabolic and fluid disturbances that may preclude the safe use of certain classes of oral antidiabetic agents. The use of some agents in the presence of renal impairment is complicated by excessive weight gain, edema, and hypoglycemia. As a result, once a patient progresses to more advanced chronic kidney disease, treatment of diabetes is typically limited to only a few therapies. Thus, there is certainly an unmet need to evaluate newer classes of antidiabetic therapies in chronic kidney disease. Incretin-based therapies, including glucagon-like peptide-1 analogs and dipeptidyl peptidase-4 (DPP-4) inhibitors, have been clinically available for several years, and may offer an effective treatment option in the presence of chronic kidney disease owing to favorable efficacy, safety, and tolerability profiles in this patient population. This communication summarizes the findings of a 1-year, randomized, double-blind, placebo-controlled study demonstrating the favorable safety and efficacy profile of linagliptin in patients with type 2 diabetes and severe renal impairment. ${ }^{1}$

The US Renal Data System annual report for 2012 estimates that the overall prevalence of chronic kidney disease (defined as glomerular filtration rate [GFR] $<60 \mathrm{~mL} / \mathrm{min} / 1.73 \mathrm{~m}^{2}$ ) has risen slightly from $12 \%$ in 1994 to $14 \%$ in $2010 .{ }^{2}$ Globally, chronic kidney disease has steadily increased over the past decade, with 
prevalence rates in many countries comparable with or higher than in the US and progressing at an estimated annual growth rate of roughly $8 \%{ }^{3}$ The most prevalent causes of renal disease are diabetes and hypertension. ${ }^{3}$ For example, in the year 2007, diabetic kidney disease was the underlying cause of more than half of end-stage renal disease cases. ${ }^{4}$

As individual risk factors, conditions such as obesity, hypertension, and cardiovascular disease are each associated with an increased risk of developing chronic kidney disease, with diabetes posing the greatest risk (odds ratio 3.38-4.08). ${ }^{2}$ Currently, the estimated prevalence of diabetic kidney disease is $3.3 \%$ of the US population, corresponding to more than 10 million people. ${ }^{5}$ The resulting national economic burden of diabetic kidney disease is astounding. In 2010, the estimated total Medicare spending for treatment of patients with diabetic kidney disease was $\$ 57.5$ billion dollars, which amounts to nearly $30 \%$ of the entire Medicare budget. ${ }^{6}$ The interplay between cardiovascular and renal disease is complex and bidirectional; cardiovascular disease can lead to renal dysfunction and, at the same time, the presence of impaired renal function can worsen cardiovascular risk. Patients with mild or moderate kidney disease, end-stage renal disease, or even proteinuria without reduced GFR are at increased risk of cardiovascular mortality. ${ }^{2}$ In addition to the atherosclerosis common to patients with type 2 diabetes and normal renal function, a higher proportion of patients with end-stage renal disease also experience chronic heart failure and sudden cardiac death. ${ }^{7}$ In this patient population, the leading cause of death is sudden cardiac failure, accounting for roughly one quarter of patient mortality. ${ }^{2}$

Therefore, looking forward to the future of the diabetes landscape, management of patients with renal and cardiovascular disease will present significant treatment challenges at global, national, and practice levels alike. The latest estimates on the rate of the global diabetes epidemic place the number of people with diabetes at 522 million by the year $2030 .{ }^{8}$ With the prevalence of diabetes expanding at such a tremendous rate, the economic burden imposed by diabetic kidney disease will continue to exert significant strain on national health care systems, while individual health care providers will more frequently be faced with the challenges associated with management of patients with type 2 diabetes and declining renal function.

Several studies have demonstrated the importance of glycemic control for the prevention of microvascular complications such as impaired renal function. ${ }^{9}$ Thus, the availability of antihyperglycemic agents that may be used in patients with declining renal function presents an important treatment advantage. McGill et al recently published a study of the DPP-4 inhibitor linagliptin in patients with severe renal impairment. ${ }^{1}$ Given its primarily hepatobiliary route of elimination from the body, ${ }^{10}$ linagliptin is approved for use in patients with declining renal function, at the same dose level as in patients with normal renal filtration. ${ }^{10}$

The study recently published by $\mathrm{McGill}$ et $\mathrm{al}^{1}$ provides the first demonstration of the long-term safety and efficacy profile of linagliptin when used in patients with severe renal impairment. This was a 1-year, randomized, double-blind, placebo-controlled study in 133 patients with estimated GFR $<30 \mathrm{~mL} / \mathrm{min} / 1.73 \mathrm{~m}^{2}$ (not requiring dialysis). Patients received linagliptin or placebo as add-on to previous stable ( $\geq 8$ weeks) therapies, which permissibly included insulin, sulfonylurea, pioglitazone, glinides, or an $\alpha$-glucosidase inhibitor. The efficacy endpoint was glycosylated hemoglobin $\left(\mathrm{HbA}_{1 \mathrm{c}}\right)$ change from baseline to week 12 (primary) and week 52 (secondary), whereas the primary safety endpoints included the frequency and intensity of adverse events, withdrawals because of adverse events, physical examinations, 12-lead electrocardiograms, vital signs, and clinical laboratory assessments throughout the study.

Treatment with linagliptin was associated with improvements in glycemic control comparable with those seen in patients with normal renal function (Figure $1 \mathrm{~A}$ and $\mathrm{B}$ ). The mean placebo-adjusted $\mathrm{HbA}_{1 \mathrm{c}}$ changes from baseline $(8.2 \% \pm 1 \%)$ were $-0.60 \%$ at week $12(95 \%$ confidence interval $[\mathrm{CI}]-0.89$ to $-0.31 ; P<0.0001)$ and $-0.72 \%$ at week 52 ( $95 \% \mathrm{CI}-1.03$ to $-0.41 ; P<0.0001)$. Importantly, a larger proportion of patients treated with linagliptin achieved $\mathrm{HbA}_{1 \mathrm{c}}<7.0 \%$ (from baseline $\mathrm{HbA}_{1 \mathrm{c}} \geq 7.0 \%$ ) compared with placebo (18\% versus $10 \%$, respectively). These values yielded an odds ratio for achieving $\mathrm{HbA}_{1 \mathrm{c}}<7.0 \%$ of 2.9 (95\% CI 0.769-10.836, $P=0.2225$ ).

In addition to demonstrating glycemic efficacy in patients with severe renal impairment, linagliptin therapy was associated with a favorable safety profile. After 52 weeks, the overall incidence of adverse events in patients receiving linagliptin was comparable with that reported for placebo (94\% versus $92 \%$ ). Among those who discontinued treatment, $12 \%$ of cases in the linagliptin group versus $17 \%$ in the placebo group were due to adverse events. The ability to offer a well tolerated antidiabetic treatment to a group of patients who are facing symptoms related to chronic kidney disease offers a tremendous potential in this setting in improving glycemic control. 
A

12 weeks

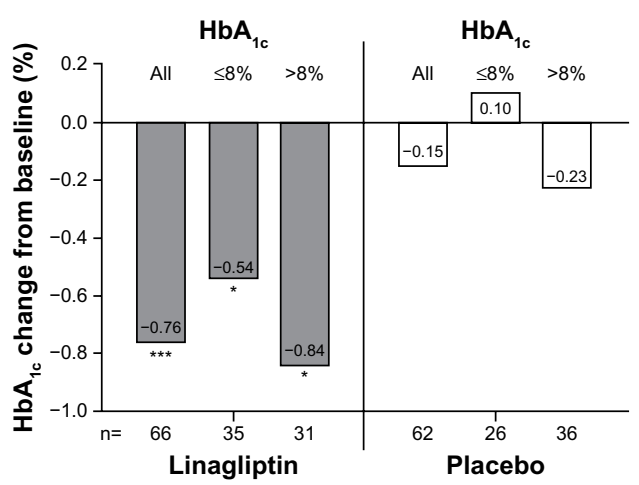

B
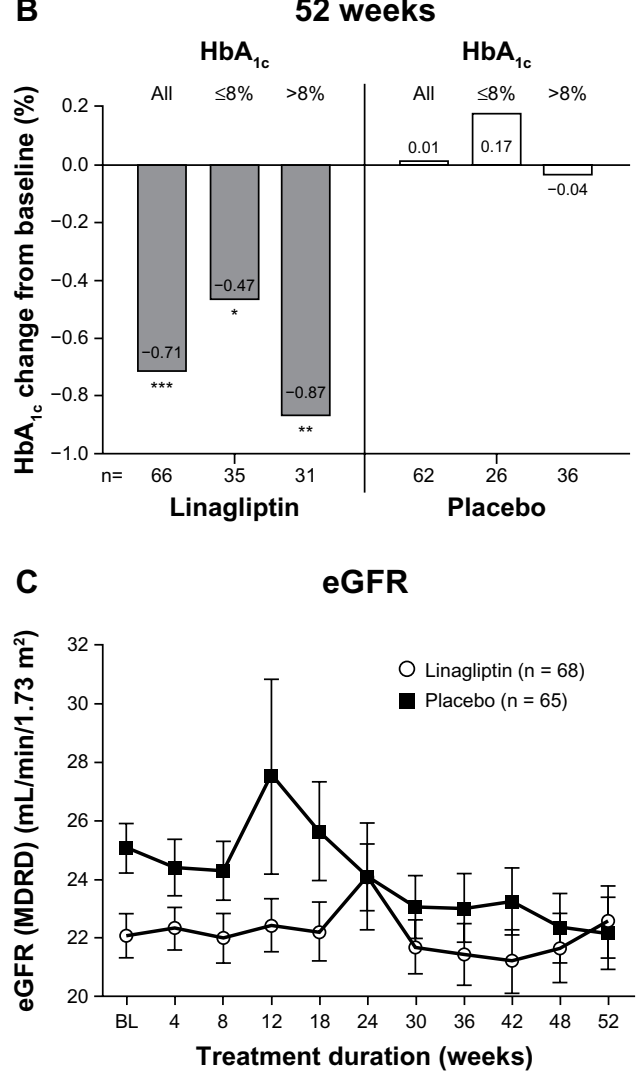

Figure I Change from baseline to (A) week 12 and (B) week 52 for the adjusted mean $\mathrm{HbA}_{\mathrm{lc}}$ in all patients and those with baseline $\mathrm{HbA}_{\mathrm{lc}} \leq 8 \%$ and $>8 \%$; (C) time course of mean estimated GFR over I year in the treated set.

Notes: $* P<0.01$; $* * P<0.00$ I; ${ }^{* * *} P<0.000$ I versus placebo. Figure IC: Copyright 2013 American Diabetes Association. From Diabetes Care ${ }^{\circledR}$, Vol 36, 2013 ; 237 244.'

Abbreviations: $\mathrm{BL}$, baseline; eGFR, estimated glomerular filtration rate; $\mathrm{HbA}_{\mathrm{Ic}}$, glycosylated hemoglobin; MDRD, Modification of Diet in Renal Disease.

A key finding from this study was that compared with placebo, treatment with linagliptin was associated with a slightly smaller decline in estimated GFR over the course of 1 year (Figure 1C). As a safety measure, renal function was monitored over regular time intervals, demonstrating a decline in estimated GFR of $-2.2 \mathrm{~mL} / \mathrm{min} / 1.73 \mathrm{~m}^{2}$ in the placebo group (from a mean $25 \mathrm{~mL} / \mathrm{min} / 1.73 \mathrm{~m}^{2}$ at baseline). In comparison, estimated GFR declined to a lesser extent in linagliptin-treated patients, ie, $-0.8 \mathrm{~mL} / \mathrm{min} / 1.73 \mathrm{~m}^{2}$ (from a mean baseline value of $22 \mathrm{~mL} / \mathrm{min} / 1.73 \mathrm{~m}^{2}$ ). The authors note that scientific caution should be exercised in the interpretation of these data, since the progressive nature of diabetic kidney disease can be influenced by multiple confounding variables that were not rigorously accounted for in this study. Nevertheless, these data suggest that linagliptin could potentially complement other therapies that preserve renal function. ${ }^{1}$ Although there have been several studies of DPP-4 inhibitors in patients with declining renal function (Table 1), it would be of benefit to patients with renal impairment if larger, well controlled studies were conducted to evaluate and reproduce the effects of these agents on the progressive decline of estimated GFR seen in patients with diabetic kidney disease. Additionally, because the study by McGill et al ${ }^{1}$ excluded patients receiving chronic dialysis, future studies of newer antidiabetic agents, such as linagliptin, in this patient population would provide useful information for the practicing clinician.

In the future, trials of longer duration would be helpful to elucidate further the effects of DPP-4 inhibitors in this patient population, particularly if such trials were to measure additional markers of renal function such as proteinuria, preservation of estimated GFR, changes in blood pressure, and incidence of cardiovascular events. Large-scale clinical trials (ClincalTrials.gov identifier) are currently in progress that will assess the long-term effects of linagliptin, saxagliptin, and sitagliptin, respectively: CAROLINA (Cardiovascular Outcome Study of Linagliptin Versus Glimepiride in Patients With Type 2 Diabetes, NCT01243424), SAVOR-TIMI 53 (Does Saxagliptin Reduce the Risk of Cardiovascular Events When Used Alone or Added to Other Diabetes Medications?, NCT01107886), and TECOS (Sitagliptin Cardiovascular Outcome Study, NCT00790205). These are large studies (6,000-16,500 patients) of long duration (4-8 years), and are designed to assess cardiovascular outcomes. Although not specifically targeted toward patients with renal impairment, the patient population (individuals with type 2 diabetes and cardiovascular disease) in each of these studies is likely to include a significant number of individuals with varying degrees of renal impairment. Of important note is that CAROLINA is the only study that designated in its prespecified inclusion criteria patients with prevalent microvascular complications, such as chronic kidney disease and/or microalbuminuria.

Thus, with completion of these studies, we can expect to see long-term data describing the use of DPP-4 inhibitors in 
Table I Studies evaluating DPP-4 inhibitors in patients with declining renal function

\begin{tabular}{|c|c|c|c|}
\hline Study & Renal function & $\begin{array}{l}\text { Change }^{a} \text { in } \\
\text { HbA }_{\mathrm{Ic}}(\%)\end{array}$ & $\begin{array}{l}\text { Patients with at } \\
\text { least one AE (\%) }\end{array}$ \\
\hline Arjona Ferreira et al" $(n=26)$ & $\mathrm{eGFR}^{\mathrm{b}}<50$ & & \\
\hline Sitagliptin (54 weeks) & & -0.8 & 68 \\
\hline Glipizide & & -0.6 & 72 \\
\hline Arjona Ferreira et $\mathrm{al}^{12}(\mathrm{n}=129)$ & ESRD with dialysis & & \\
\hline Sitagliptin (54 weeks) & & -0.72 & 83 \\
\hline Glipizide & & -0.87 & 80 \\
\hline Kothny et $\mathrm{al}^{13}(\mathrm{n}=369)$ & eGFR:b & & \\
\hline \multirow[t]{2}{*}{ Vildagliptin (54 weeks) } & $\geq 30$ to $<50$ & -0.6 & 84 \\
\hline & $<30$ & -0.8 & 85 \\
\hline \multirow[t]{2}{*}{ Placebo } & $\geq 30$ to $<50$ & -0.2 & 85 \\
\hline & $<30$ & -0.1 & 88 \\
\hline McGill et al' $(n=133)$ & $\mathrm{eGFR}^{\mathrm{b}}<30$ without dialysis & & \\
\hline Linagliptin (52 weeks) & & $-0.72^{c}$ & 94 \\
\hline Placebo & & & 92 \\
\hline Nowicki et al ${ }^{14}(n=164)$ & $\mathrm{CrCl}:{ }^{\mathrm{d}}$ & & \\
\hline \multirow[t]{2}{*}{ Saxagliptin (52 weeks) } & $\leq 60$ & -0.94 & 58 \\
\hline & $\leq 30$ & -0.81 & 83 \\
\hline \multirow[t]{2}{*}{ Placebo } & $\leq 60$ & +0.19 & 60 \\
\hline & $\leq 30$ & -0.49 & 70 \\
\hline
\end{tabular}

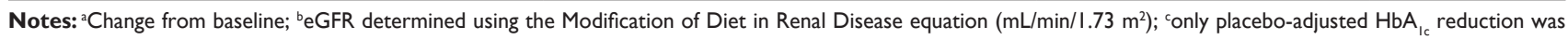
reported; ${ }^{d} \mathrm{CrCl}$ determined using the Cockcroft-Gault equation $(\mathrm{mL} / \mathrm{min})$.

Abbreviations: DPP-4, dipeptidyl peptidase-4; $\mathrm{HbA}_{\mathrm{lc}}$, glycosylated hemoglobin; AE, adverse event; eGFR, estimated glomerular filtration rate; ESRD, end-stage renal disease; $\mathrm{CrCl}$, creatinine clearance.

patients with renal and cardiovascular disease. The current literature evaluating these agents supports their relative safety and efficacy in patients with declining renal function.

\section{Disclosure}

The author was fully responsible for all content and editorial decisions, was involved at all stages of manuscript development, and approved the final version of the review reflecting the author's interpretation and conclusions. Boehringer Ingelheim was given the opportunity to check the data used in the manuscript for factual accuracy only. Medical writing assistance, supported financially by Boehringer Ingelheim, was provided by Michael P Bennett and Linda Merkel of Envision Scientific Solutions during preparation of this paper.

\section{References}

1. McGill JB, Sloan L, Newman J, et al. Long-term efficacy and safety of linagliptin in patients with type 2 diabetes and severe renal impairment: a 1-year, randomized, double-blind, placebo-controlled study. Diabetes Care. 2013;36(2):237-244.

2. United States Renal Data System. USRDS 2012 annual data report: atlas of chronic kidney disease and end-stage renal disease in the United States; 2012. Available from: http://www.usrds.org/atlas.aspx. Accessed July 16, 2013.

3. White SL, Chadban SJ, Jan S, Chapman JR, Cass A. How can we achieve global equity in provision of renal replacement therapy? Bull World Health Organ. 2008;86(3):229-237.
4. United States Renal Data System. USRDS 2009 annual data report: atlas of chronic kidney disease and end-stage renal disease in the United States; 2009. Available from: http://www.usrds.org/atlas09.aspx. Accessed July 16, 2013.

5. de Boer IH, Rue TC, Hall YN, Heagerty PJ, Weiss NS, Himmelfarb J. Temporal trends in the prevalence of diabetic kidney disease in the United States. JAMA. 2011;305(24):2532-2539.

6. National Kidney Foundation. USRDS 2010 annual data report: kidney disease by the numbers; 2010. Available from: http://www.kidney. org/advocacy/pdf/KIDNEY_DISEASE_BY_THE_NUMBERS.pdf. Accessed July 16, 2013.

7. Heidemann C, Boeing H, Pischon T, Nothlings U, Joost HG, Schulze MB. Association of a diabetes risk score with risk of myocardial infarction, stroke, specific types of cancer, and mortality: a prospective study in the European Prospective Investigation into Cancer and Nutrition (EPIC)-Potsdam cohort. Eur J Epidemiol. 2009;24(6): 281-288.

8. International Diabetes Federation. Diabetes Atlas. 5th ed; 2012. Available from: http://www.idf.org/diabetesatlas/5e/the-global-burden. Accessed July 16, 2013.

9. Skyler JS, Bergenstal R, Bonow RO, et al. Intensive glycemic control and the prevention of cardiovascular events: implications of the ACCORD, ADVANCE, and VA diabetes trials: a position statement of the American Diabetes Association and a scientific statement of the American College of Cardiology Foundation and the American Heart Association. Circulation. 2009;119(2):351-357.

10. Boehringer Ingelheim Pharmaceuticals Inc. Tradjenta (linagliptin) tablets prescribing information; 2011 (updated 2013 June). Available from: http://bidocs.boehringer-ingelheim.com/BIWebAccess/ViewServlet. ser? docBase=renetnt $\&$ folderPath=/Prescribing+Information/PIs/ Tradjenta/Tradjenta.pdf. Accessed July 16, 2013.

11. Arjona Ferreira JC, Marre M, Barzilai N, et al. Efficacy and safety of sitagliptin versus glipizide in patients with type 2 diabetes and moderate-to-severe chronic renal insufficiency. Diabetes Care. 2013;36(5):1067-1073. 
12. Arjona Ferreira JC, Corry D, Mogensen CE, et al. Efficacy and safety of sitagliptin in patients with type 2 diabetes and ESRD receiving dialysis: a 54-week randomized trial. Am J Kidney Dis. 2013;61(4):579-587.

13. Kothny W, Shao Q, Groop PH, Lukashevich V. One-year safety, tolerability and efficacy of vildagliptin in patients with type 2 diabetes and moderate or severe renal impairment. Diabetes Obes Metab. 2012;14(11):1032-1039.
14. Nowicki M, Rychlik I, Haller H, et al. Long-term treatment with the dipeptidyl peptidase- 4 inhibitor saxagliptin in patients with type 2 diabetes mellitus and renal impairment: a randomised controlled 52-week efficacy and safety study. Int J Clin Pract. 2011;65(12): $1230-1239$.

\section{Publish your work in this journal}

Diabetes, Metabolic Syndrome and Obesity: Targets and Therapy is an international, peer-reviewed open-access journal committed to the rapid publication of the latest laboratory and clinical findings in the fields of diabetes, metabolic syndrome and obesity research. Original research, review, case reports, hypothesis formation, expert opinion and commentaries are all considered for publication. The manuscript management system is completely online and includes a very quick and fair peer-review system, which is all easy to use. Visit http://www.dovepress.com/testimonials.php to read real quotes from published authors.

Submit your manuscript here: http://www.dovepress.com/diabetes-metabolic-syndrome-and-obesity-targets-and-therapy-journal 